\title{
Correction to: Unpacking Configurational Dynamics: Sequence Analysis and Qualitative Comparative Analysis as a Mixed-Method Design
}

\author{
Camilla Borgna and Emanuela Struffolino
}

\section{Correction to:}

Chapter 10 in: G. Ritschard, M. Studer (eds.), Sequence Analysis and Related Approaches, Life Course Research and Social Policies 10, https://doi.org/10.1007/978-3-319-95420-2_10

In the original version of this book, the second author Emanuela Struffolino was missed to be added as the corresponding author and the affiliation of the author Camilla Borgna was incorrect. The second author Emanuela Struffolino has now also been included as the corresponding author and the affiliation of Camilla Borgna is corrected as Collegio Carlo Alberto, Turin, Italy.

The updated online version of this chapter can be found at https://doi.org/10.1007/978-3-319-95420-2_10 